\title{
Strain and morphology compliance during the intentional doping of high-Al-content AlGaN layers
}

\author{
Daniel Nilsson, Erik Janzén and Anelia Kakanakova-Georgieva
}

\section{Linköping University Post Print}

\section{Tweet}

N.B.: When citing this work, cite the original article.

Original Publication:

Daniel Nilsson, Erik Janzén and Anelia Kakanakova-Georgieva, Strain and morphology compliance during the intentional doping of high-Al-content AlGaN layers, 2014, Applied Physics Letters, (105), 8, 082106.

http://dx.doi.org/10.1063/1.4894173

Copyright: American Institute of Physics (AIP) http://www.aip.org/

Postprint available at: Linköping University Electronic Press http://urn.kb.se/resolve?urn=urn:nbn:se:liu:diva-106723 


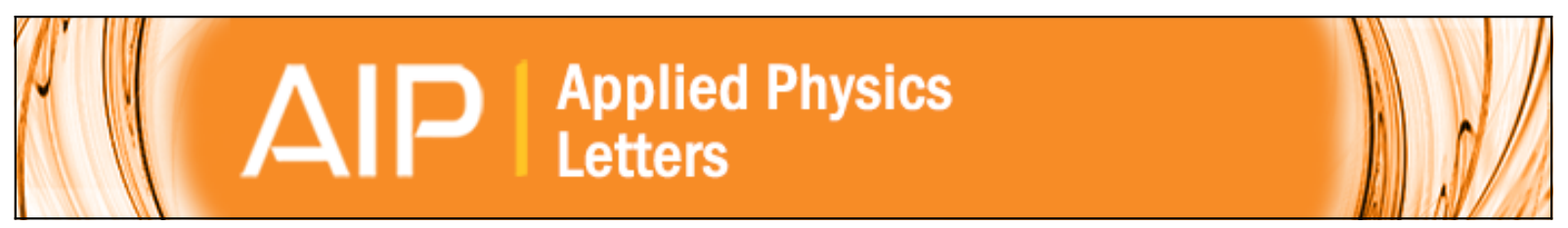

\section{Strain and morphology compliance during the intentional doping of high-Al-content} AIGaN layers

D. Nilsson, E. Janzén, and A. Kakanakova-Georgieva

Citation: Applied Physics Letters 105, 082106 (2014); doi: 10.1063/1.4894173

View online: http://dx.doi.org/10.1063/1.4894173

View Table of Contents: http://scitation.aip.org/content/aip/journal/apl/105/8?ver=pdfcov

Published by the AIP Publishing

\section{Articles you may be interested in}

Inhomogeneous distribution of defect-related emission in Si-doped AIGaN epitaxial layers with different Al content and Si concentration

J. Appl. Phys. 115, 053509 (2014); 10.1063/1.4864020

Mg doping for p-type AllnN lattice-matched to GaN

Appl. Phys. Lett. 101, 082113 (2012); 10.1063/1.4747524

Silicon concentration dependence of optical polarization in AIGaN epitaxial layers

Appl. Phys. Lett. 98, 021910 (2011); 10.1063/1.3543631

High-temperature molecular beam epitaxial growth of $\mathrm{AIGaN} / \mathrm{GaN}$ on $\mathrm{GaN}$ templates with reduced interface impurity levels

J. Appl. Phys. 107, 043527 (2010); 10.1063/1.3285309

Investigation of Mg doping in high-Al content p -type Al x Ga $1-x \mathrm{~N}(0.3 \times 0.5)$

Appl. Phys. Lett. 86, 082107 (2005); 10.1063/1.1867565

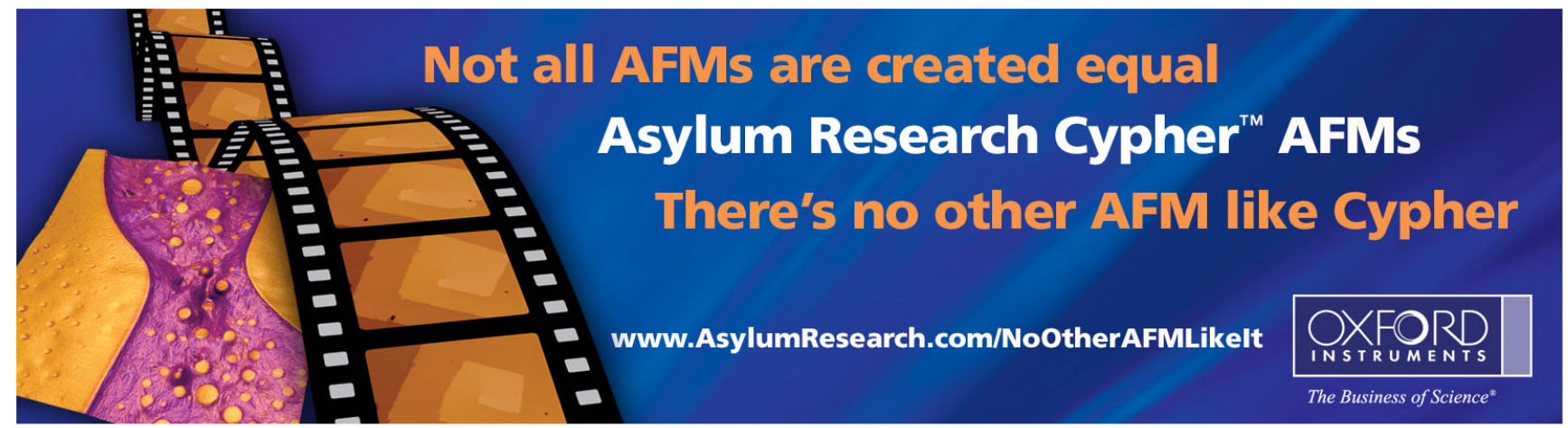




\title{
Strain and morphology compliance during the intentional doping of high-Al-content AIGaN layers
}

\author{
D. Nilsson, E. Janzén, and A. Kakanakova-Georgieva ${ }^{\text {a) }}$ \\ Department of Physics, Chemistry and Biology (IFM), Linköping University, SE-58183 Linköping, Sweden
}

(Received 1 March 2014; accepted 10 August 2014; published online 26 August 2014)

\begin{abstract}
This study presents analysis of the residual strain and related surface morphology of high-Alcontent $\mathrm{Al}_{0.82} \mathrm{Ga}_{0.18} \mathrm{~N}$ layers doped by silicon up to the level of $3 \times 10^{19} \mathrm{~cm}^{-3}$. We focus on understanding the basic mechanisms which underlie the formation of the distinct surface morphology of the $\mathrm{Al}_{0.82} \mathrm{Ga}_{0.18} \mathrm{~N}$ :Si layers and their conductivity. We discuss the development of certain facet structure (nanopipes) within the doped layers, which is apparent at the high Si doping levels. The formation of nanopipes influences the conductivity of the layers. It is anticipated to give rise to facets with $\mathrm{SiN}$-related coverage, outcompeting the incorporation of $\mathrm{Si}$ at substitutional donor sites in the lattice. We do not find evidence for kinetic stabilization of preferential crystallographic facets when a dopant flow of bis(cyclopentadienyl)magnesium $\left(\mathrm{Cp}_{2} \mathrm{Mg}\right)$, instead of silane $\left(\mathrm{SiH}_{4}\right)$, is implemented in the doping process. (C) 2014 AIP Publishing LLC.

[http://dx.doi.org/10.1063/1.4894173]
\end{abstract}

The light-emitting device structures intended for operation at the short wavelengths in the deep-ultraviolet, $\lambda<280 \mathrm{~nm}$, are based on the wide-band-gap $\mathrm{Al}_{\mathrm{x}} \mathrm{Ga}_{1-\mathrm{x}} \mathrm{N}$ material system, $x>0.70$. The vast majority of these $\mathrm{Al}_{\mathrm{x}} \mathrm{Ga}_{1-\mathrm{x}} \mathrm{N}$-based device structures is yet grown on $\mathrm{SiC}$, alternatively sapphire, substrates. These device structures incorporate the following layer sequence, $\mathrm{Al}_{\mathrm{x}} \mathrm{Ga}_{1-\mathrm{x}} \mathrm{N}: \mathrm{Si} / \mathrm{Al}_{\mathrm{x}} \mathrm{Ga}_{1-\mathrm{x}} \mathrm{N} / \mathrm{AlN}$-on-SiC. The Si-doped $\mathrm{Al}_{\mathrm{x}} \mathrm{Ga}_{1-\mathrm{x}} \mathrm{N}$ layer, $\mathrm{Al}_{\mathrm{x}} \mathrm{Ga}_{1-\mathrm{x}} \mathrm{N}: \mathrm{Si}$, provides the n-type carriers for the electrical pumping of the devices. The growth of the $\mathrm{Al}_{\mathrm{x}} \mathrm{Ga}_{1-\mathrm{x}} \mathrm{N}$ layers is affected by a specific complexity. A tensile-stress-gradient is generated along the growth direction, which is related to the inclination of pure edge threading dislocations $^{1,2}$ propagating from the AlN layer and originating at the interface with the foreign substrate. Thermodynamic calculations based on bulk-energy-balance provide a set of conditions for the onset of the dislocation inclination. ${ }^{3,4}$ The existence of an energy barrier of up to $10 \mathrm{eV}$ to dislocation inclination is indicated for thin stressed layers. This high energy barrier is considered to be reduced if surface roughening evolves, which depends on the implemented growth rate, temperature, and doping levels. ${ }^{5}$ The tensile-stress-gradient causes gradual relaxation of the initial compressive strain in various $\mathrm{Al}_{\mathrm{x}} \mathrm{Ga}_{1-\mathrm{x}} \mathrm{N}$ layers grown on $\mathrm{Al}(\mathrm{Ga}) \mathrm{N}$ templates by MOCVD. ${ }^{2-10}$ The gradual relaxation of the initially compressive $\mathrm{Al}_{\mathrm{x}} \mathrm{Ga}_{1-\mathrm{x}} \mathrm{N}$ layer is followed by a transition to tensile strain, and enhancement of the tensile strain at the onset of the Si doping. ${ }^{8,10}$ This specific growth feature has typically been extracted from in-situ curvature measurements and analysis of stress generation during epitaxial growth. ${ }^{8,10}$ The propagation of tensile strain in the $\mathrm{Al}_{\mathrm{x}} \mathrm{Ga}_{1-\mathrm{x}} \mathrm{N}$ :Si layer and potential cracks limits the range of targeted thickness and $\mathrm{Si}$ doping levels for optimal performance of the n-type layers incorporated in the $\mathrm{Al}_{\mathrm{x}} \mathrm{Ga}_{1-\mathrm{x}} \mathrm{N}$-based light-emitting device structures. It has been established that the amount of the tensile-strain-gradient increases (i) with the increase in $\mathrm{Si}$ doping for the same $\mathrm{Al}_{\mathrm{x}} \mathrm{Ga}_{1-\mathrm{x}} \mathrm{N}$ composition, (ii) for higher-Al-content $\mathrm{Al}_{\mathrm{x}} \mathrm{Ga}_{1-\mathrm{x}} \mathrm{N}$

\footnotetext{
${ }^{\text {a) }}$ Author to whom correspondence should be addressed. Electronic mail: anelia@ifm.liu.se.
}

layers at the same $\mathrm{Si}$ doping level, and (iii) for thicker $\mathrm{Al}_{\mathrm{x}} \mathrm{Ga}_{1-\mathrm{x}} \mathrm{N}$ :Si layers of the same composition and $\mathrm{Si}$ doping level. ${ }^{8}$ Previous studies relate to $\mathrm{Al}_{\mathrm{x}} \mathrm{Ga}_{1-\mathrm{x}} \mathrm{N}: \mathrm{Si}$ layers of $x \sim 0.40-0.60 .^{8}$ The most recent study reports on an alloy composition of $x \sim 0.20-0.90 .^{10}$

By performing ex-situ X-ray diffraction (XRD) measurements, we can confirm the same trends, (i)-(iii), of tensile strain propagation for $\mathrm{Al}_{\mathrm{x}} \mathrm{Ga}_{1-\mathrm{x}} \mathrm{N}$ :Si layers of high-Al-content, $x \sim 0.70-0.90$. For the present study, we select layers of the same alloy composition, $x \sim 0.82$, and thickness, $\sim 400 \mathrm{~nm}$, doped by $\mathrm{Si}$ at several different levels, up to $[\mathrm{Si}] \sim 3 \times 10^{19} \mathrm{~cm}^{-3}$. We focus on understanding the basic mechanisms which underlie the formation of the distinct surface morphology of the $\mathrm{Al}_{0.82} \mathrm{Ga}_{0.18} \mathrm{~N}$ :Si layers and the performance of their transport properties. We discuss the development of certain facet structure (nanopipes) within the layers, which is apparent at higher Si doping levels. The development of nanopipes influences the transport properties of the layers. It is anticipated to give rise to facets with SiNrelated coverage, outcompeting the incorporation of $\mathrm{Si}$ at substitutional donor sites in the lattice.

In this study, $\mathrm{Al}_{\mathrm{x}} \mathrm{Ga}_{1-\mathrm{x}} \mathrm{N}$ :Si/ $\mathrm{Al}_{\mathrm{x}} \mathrm{Ga}_{1-\mathrm{x}} \mathrm{N} / \mathrm{AlN}$ structures were grown on semi-insulating $4 \mathrm{H}-\mathrm{SiC}$ substrates in a horizontal hot-wall MOCVD reactor (GR508GFR AIXTRON). The reactor was operated at a process pressure of 50 mbar. Trimethylaluminum (TMAl), trimethylgallium (TMGa), and ammonia $\left(\mathrm{NH}_{3}\right)$ were the principal precursors in the deposition process, with silane $\left(\mathrm{SiH}_{4}\right)$ and bis(cyclopentadienyl) magnesium $\left(\mathrm{Cp}_{2} \mathrm{Mg}\right)$ as dopant precursors. The effective substrate template, AlN-on-SiC, was overgrown by a composition-graded $\mathrm{Al}_{\mathrm{x}} \mathrm{Ga}_{1-\mathrm{x}} \mathrm{N}$ layer with $x$ decreasing from 1.0 to a certain targeted value by lowering the process temperature from $1240{ }^{\circ} \mathrm{C}$ (the typical process temperature for AlN growth) to $1100^{\circ} \mathrm{C}$ (the typical process temperature for $\mathrm{Al}_{\mathrm{x}} \mathrm{Ga}_{1-\mathrm{x}} \mathrm{N}$ growth). During the deposition of the graded layer, TMGa was introduced at a constant gas-flow-rate corresponding to the targeted value, $x$, of the alloy composition. This approach was implemented only in the growth of the layer structures doped by $\mathrm{Si}$. The concentration of dopants 
and residual impurities, and the alloy composition, was measured by secondary ion mass spectrometry (SIMS, Evans Analytical Group), i.e., with a single technique and irrespective of their site in the crystal lattice, and lattice distortions. The alloy composition determined by SIMS corresponded to $\mathrm{Al}_{0.77} \mathrm{Ga}_{0.23} \mathrm{~N}$, as already reported. ${ }^{11}$ XRD measurements were carried out in a PANalytical Empyrean diffractometer using $\mathrm{Cu} \mathrm{K}_{\alpha 1}$-radiation at a wavelength of $\lambda=1.5406 \AA$. Reciprocal space maps were taken around the asymmetric 10-15 reflection in $\mathrm{Al}_{\mathrm{X}} \mathrm{Ga}_{1-\mathrm{x}} \mathrm{N}$. It is recalled that in this case, the abscissa $Q_{X}=\lambda /(a \sqrt{3})$, and the ordinate $Q_{Z}=5 \lambda / 2 c$, where $\lambda$ is the wavelength of the $x$-ray radiation used..$^{9,12}$ The extraction of the lattice parameters, $a$ and $c$, and the commonly followed subsequent analysis-which assumes a certain relation between the in-plane and out-of plane strain and the applicability of the Vegard's law ${ }^{9,12}$-allows the alloy composition, $x$, and residual strain (respectively stress) to be calculated. The in-plain residual stress, $\sigma_{X X}$, in the $\mathrm{Al}_{\mathrm{X}} \mathrm{Ga}_{1-\mathrm{x}} \mathrm{N}$ layers, is represented by: $\sigma_{\mathrm{XX}}=\left[\mathrm{C}_{11}(x)\right.$ $\left.+\mathrm{C}_{12}(x)-2 \quad \mathrm{C}_{13}{ }^{2}(x) / \mathrm{C}_{33}(x)\right]\left[\left(a-a_{0}(x)\right) / a_{0}(x)\right]$, where the term $\left(a-a_{0}(x)\right) / a_{0}(x)$ expresses the in-plane strain, $a_{0}(x)$ is the strain-free lattice constant, and $\mathrm{C}_{\mathrm{ij}}(x)$ is the elastic constant, respectively, of $\mathrm{Al}_{\mathrm{x}} \mathrm{Ga}_{1-\mathrm{x}} \mathrm{N}$ alloy. These parameter values were determined assuming that the Vegard's law is valid and following a linear interpolation between the values for GaN and AIN (Table I). The alloy composition extracted from XRD corresponds to $\mathrm{Al}_{0.82} \mathrm{Ga}_{0.18} \mathrm{~N}$, i.e., it is equivalent to the SIMS determined alloy composition within 0.05. The alloy composition extracted from XRD is referred to throughout the article text. The surface morphology of the layers was studied in a Veeco Dimension 3100 atomic force microscope (AFM) operating in tapping mode. The rootmean-square roughness of the surface (rms) was extracted from scans at a scale of $2 \times 2 \mu \mathrm{m}^{2}$.

In the following, we present analysis of the residual strain and related surface morphology of $\mathrm{Al}_{0.82} \mathrm{Ga}_{0.18} \mathrm{~N}: \mathrm{Si}$ layers. $\mathrm{Al}_{0.82} \mathrm{Ga}_{0.18} \mathrm{~N}$ :Si layers of two characteristic doping levels were selected: [Si] $2 \times 10^{18} \mathrm{~cm}^{-3}$, which gives rise to transport properties on-par with the best up-to-date reported values in terms of carrier concentration and mobility, and $[\mathrm{Si}] \sim 1 \times 10^{19} \mathrm{~cm}^{-3}$, which results in high resistivity. ${ }^{11}$ Except for the $\mathrm{Si}$ doping level, other growth conditions were otherwise identical. The set of layer structures was complemented by a structure doped to the even higher level of $[\mathrm{Si}] \sim 3 \times 10^{19} \mathrm{~cm}^{-3}$ under the same identical growth conditions.

As already pointed out, a characteristic tensile-stressgradient develops in a typical $\mathrm{Al}_{\mathrm{x}} \mathrm{Ga}_{1-\mathrm{x}} \mathrm{N}: \mathrm{Si} / \mathrm{Al}_{\mathrm{x}} \mathrm{Ga}_{1-\mathrm{x}} \mathrm{N} /$ AlN-on-SiC structure, which not only relaxes the initially compressive $\mathrm{Al}_{\mathrm{x}} \mathrm{Ga}_{1-\mathrm{x}} \mathrm{N}$ layer but also contributes to transition to a tensile strain. ${ }^{8}$ The onset of the Si doping is shown

TABLE I. Lattice parameters and elastic constants of AlN and $\mathrm{GaN}^{13}$ used to calculate the $\mathrm{Al}_{\mathrm{x}} \mathrm{Ga}_{1-\mathrm{x}} \mathrm{N}$ alloy composition, $x$, strain-free lattice parameters, $a_{0}(x)$ and $c_{0}(x)$, and elastic constants $\mathrm{C}_{\mathrm{ij}}(x)$

\begin{tabular}{ccccccc}
\hline \hline & $a^{0}(\AA)$ & $c^{0}(\AA)$ & $\mathrm{C}^{11}(\mathrm{GPa})$ & $\mathrm{C}^{12}(\mathrm{GPa})$ & $\mathrm{C}^{13}(\mathrm{GPa})$ & $\mathrm{C}^{33}(\mathrm{GPa})$ \\
\hline $\mathrm{AlN}$ & 3.11197 & 4.98089 & 395 & 137 & 107 & 404 \\
$\mathrm{GaN}$ & 3.18840 & 5.18500 & 374 & 138 & 101 & 395 \\
\hline \hline
\end{tabular}

to add a tensile stress component and a higher doping level causes the built-up of a larger tensile strain near the surface at the growth temperature. ${ }^{8,10}$ It is evident from the reciprocal space maps taken around the asymmetric 10-15 reflection in $\mathrm{Al}_{0.82} \mathrm{Ga}_{0.18} \mathrm{~N}$, Figs. 1(a)-1(c), that there is a progressive displacement of the reciprocal lattice points along a lower value of the abscissa, $Q_{X}$, which corresponds to a larger value of the lattice constant, $a$. It is apparent for the strain development in the $\mathrm{Al}_{0.82} \mathrm{Ga}_{0.18} \mathrm{~N}$ :Si layers when a larger $\mathrm{SiH}_{4}$ flow was added to the deposition process. At the same time, various degree of relaxation of the growth stress may have occurred during the cooling down of the structures, and it is in this context that the ex-situ XRD and AFM measurements have to be considered. The in-plane residual stress associated with the doping level of $[\mathrm{Si}] \sim 2 \times 10^{18} \mathrm{~cm}^{-3}$ is compressive, $\sigma_{\mathrm{XX}} \sim-0.67 \mathrm{GPa}$, by considering the single diffraction maximum contributed by the $\mathrm{Al}_{0.82} \mathrm{Ga}_{0.18} \mathrm{~N}$ reflection, Fig. 1(a). There is a formation of additional diffraction maximum along a lower value of the abscissa $Q_{X}$ for the $\mathrm{Al}_{0.82} \mathrm{Ga}_{0.18} \mathrm{~N}$ structures doped at $[\mathrm{Si}] \sim 1 \times 10^{19} \mathrm{~cm}^{-3}$, Fig. 1(b), and [Si] $\sim 3 \times 10^{19} \mathrm{~cm}^{-3}$, Fig. 1(c). This additional diffraction maximum is representative for in-plane residual tensile stress of $\sigma_{\mathrm{XX}} \sim+0.82 \mathrm{GPa}$, and $\sigma_{\mathrm{XX}} \sim+0.26 \mathrm{GPa}$, respectively. It is interpreted here as indicative for the
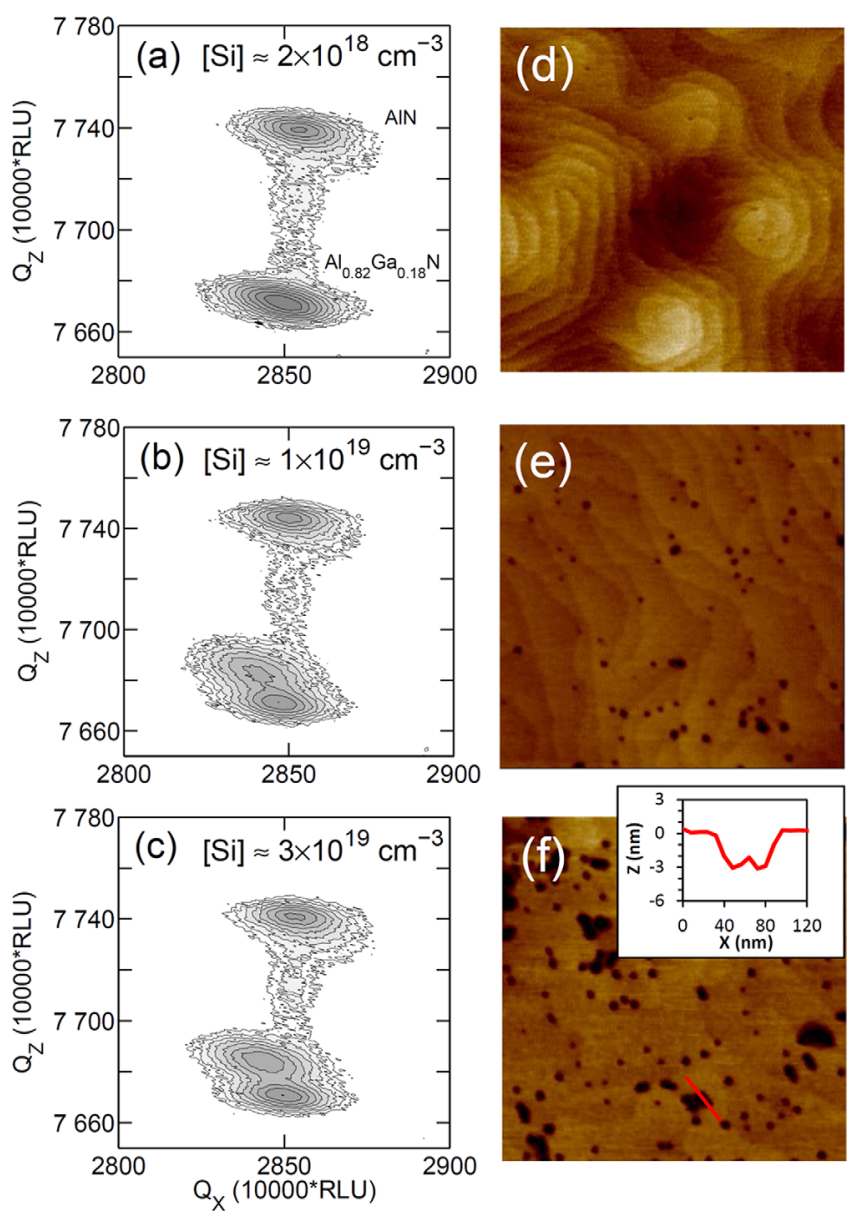

FIG. 1. Reciprocal space maps in the vicinity of the asymmetric (10-15) reciprocal lattice points measured for $\mathrm{Al}_{0.82} \mathrm{Ga}_{0.18} \mathrm{~N}$ : $\mathrm{Si}_{1} / \mathrm{Al}_{0.82} \mathrm{Ga}_{0.18} \mathrm{~N} / \mathrm{AlN}$-on$\mathrm{SiC}$ structures doped to the level of $[\mathrm{Si}] \sim 2 \times 10^{18} \mathrm{~cm}^{-3}$ (a), $1 \times 10^{19} \mathrm{~cm}^{-3}$ (b), and $3 \times 10^{19} \mathrm{~cm}^{-3}$ (c). AFM images at the scale of $1 \times 1 \mu \mathrm{m}^{2}$, (d)-(f), taken from the top surface of the respective layer structures. 
near-surface relaxation of the tensile strain built-up in the respective layers at the growth temperature.

The apparent relaxation of the tensile strain near the surface of the $\mathrm{Al}_{0.82} \mathrm{Ga}_{0.18} \mathrm{~N}$ :Si layers is reflected into their surface morphology. A step-terminated surface is connected to the case of the residual tensile stress of $\sigma_{\mathrm{XX}} \sim+0.82 \mathrm{GPa}$, Fig. 1(e). In comparison with the surface steps in this particular case, the surface steps in the case of the residual compressive stress, $\sigma_{\mathrm{XX}} \sim-0.67 \mathrm{GPa}$, appear as folded 3D-like spiral features, Fig. 1(d), while in the case of the more relaxed tensile stress, $\sigma_{\mathrm{XX}} \sim+0.26 \mathrm{GPa}$, the surface steps are totally unfolded and blurred, Fig. 1(f). It can be inferred that the strain relaxation in the near-surface of the $\mathrm{Al}_{0.82} \mathrm{Ga}_{0.18} \mathrm{~N}$ :Si layers has occurred through evolution of the surface morphology. Evolution of the surface morphology can be driven by the counterbalance between the surface free energy and the bulk strain energy near the surface. ${ }^{14}$ It has been reported that both the sign and the magnitude of the bulk strain near the surface define the surface morphology and understood as due to compressive-strain-induced lowering of the surface step free energy. ${ }^{14}$ Thereby, a tensile strain is considered to promote a flat surface, as opposite to compressive strain. In our particular case, the highest doping level of [Si] $3 \times 10^{19} \mathrm{~cm}^{-3}$ must have caused the built-up of the largest tensile strain near the surface at the growth temperature. Subsequently, this largest tensile strain drives the most significant evolution in the surface morphology as reflected in the totally unfolded and blurred surface steps on the AFM image in Fig. 1(f).

Following the promotion of a flat surface on a macroscopic micrometer-sized scale, Fig. 1(f), further relaxation of the top surface of the $\mathrm{Al}_{0.82} \mathrm{Ga}_{0.18} \mathrm{~N}$ layer doped to the highest level of $[\mathrm{Si}] \sim 3 \times 10^{19} \mathrm{~cm}^{-3}$ can be related to the generation of certain faceted pits/trenches. A number of shallow $(<10 \mathrm{~nm})$ faceted trenches undergoing extension and merging are noted (the inset in Fig. 1(f)), which cause the enhanced rms-value in the respective trend in Fig. 2. The trenches occur in addition to the incidence of nanopits dominating the surface morphology at the doping level of $[\mathrm{Si}] \sim 1 \times 10^{19} \mathrm{~cm}^{-3}$, Fig. 1(e). The nanopits may be related to nanopipes as addressed further in the text. Although the generation of the shallow faceted trenches leads to a larger surface area, an overall relaxation is presumed due to the local relief of the stored tensile strain energy. ${ }^{15,16}$ As reported in previous studies, the $\{1-101\}$ facets, associated with the characteristic trenches, are elastically relaxed. ${ }^{15}$ Any final stage of surface relaxation would consist in cracking of the layers as we have previously observed in the extreme case of heavy doping of $[\mathrm{Si}] \sim 1 \times 10^{20} \mathrm{~cm}^{-3} .11$

We next consider the nanopits dominating the surface morphology at the doping level of $[\mathrm{Si}] \sim 1 \times 10^{19} \mathrm{~cm}^{-3}$, Fig. 1(e), and presumably related to nanopipes. It cannot be excluded that some pits may be related to other types of defects. It is reinforced here that the $\mathrm{Al}_{0.82} \mathrm{Ga}_{0.18} \mathrm{~N}: \mathrm{Si}$ layers of pit-free morphology are conductive, opposite to the $\mathrm{Al}_{0.82} \mathrm{Ga}_{0.18} \mathrm{~N}$ :Si layers of pit-populated morphology, which are highly resistive. ${ }^{11}$ It is tempting to assume that the lack of conductivity is due to the lack of silicon incorporation at substitutional donor sites in the lattice, while there is a predominant formation of nanopipes with SiN-related coverage.
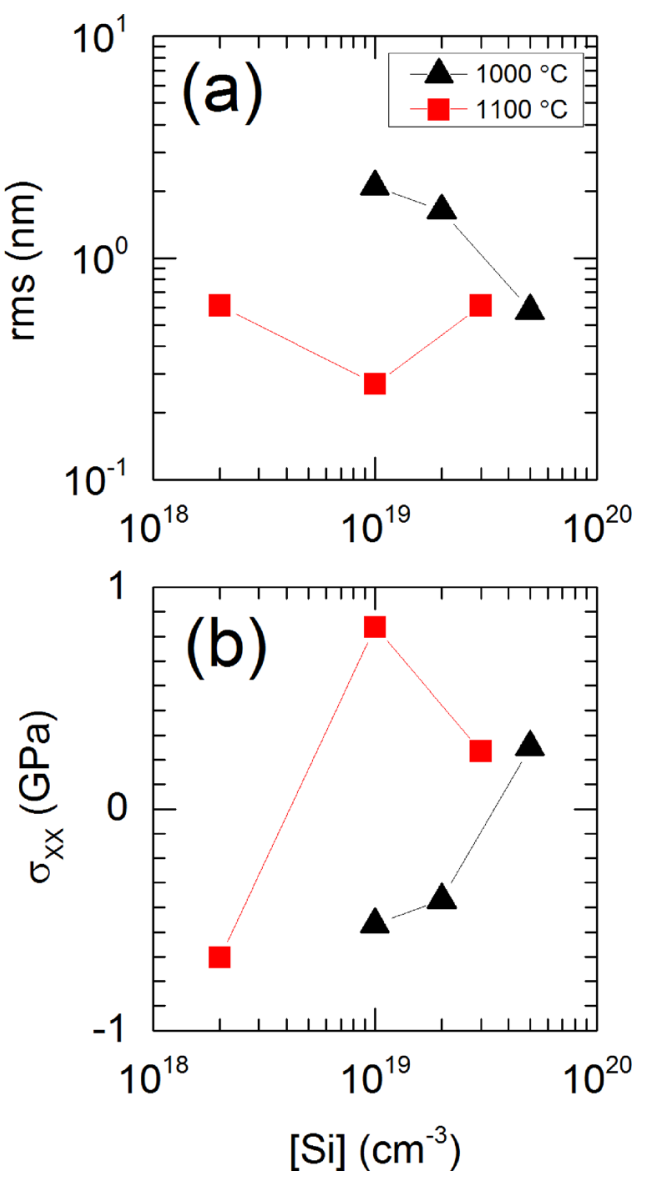

FIG. 2. Root-mean-square roughness of the surface, rms (a) and in-plane residual stress, $\sigma_{\mathrm{XX}}$ (b) vs. Si doping level in $\mathrm{Al}_{0.82} \mathrm{Ga}_{0.18} \mathrm{~N}$ layer structures grown at process temperature of $1100{ }^{\circ} \mathrm{C}$. The rms-values are representative for a scale of $2 \times 2 \mu \mathrm{m}^{2}$. Complementary data for $\mathrm{Al}_{0.79} \mathrm{Ga}_{0.21} \mathrm{~N}$ layer structures grown at lower process temperature of $1000^{\circ} \mathrm{C}$ are presented. Due to the lower process temperature, which limits the surface diffusion, the absolute rms-values in this case are generally higher. The point of the lowest rms-value/highest value of the $\sigma_{\mathrm{XX}}$ is shifted to a higher Si doping level consistent with the lower Al-content.

A mechanism, leading to the formation of nanopipes with SiN-coated sidewalls along (10-10), has been speculated on the basis of first-principle calculations applied to GaN, and considering the formation of stable and electrically inert complex, whereby $\mathrm{Ga}$ vacancies are surrounded by $\mathrm{Si}$ at a Ga site. ${ }^{17}$ We next present evidence to support the assumption for the formation of facet structure within the Si-doped $\mathrm{Al}_{0.82} \mathrm{Ga}_{0.18} \mathrm{~N}$ layer. Gradual increase of the concentration of oxygen, and carbon, is observed in a representative SIMS depth profile within the Si-doped $\mathrm{Al}_{0.82} \mathrm{Ga}_{0.18} \mathrm{~N}$ layer (Fig. 3 ). The gradual increase of the oxygen concentration indicates the development of larger surface area available for the adsorption of oxygen present on the surface during the growth. It can result from favorable formation of nanopipes with sidewalls along (10-10) within the doped layer. The (10-10) planes are known for their potential for preferential oxygen adsorption. ${ }^{17,18}$ Nanopipes can be recognized by their bright contrast in cathodoluminescence measurements, ${ }^{20}$ and we have previously reported on their observation for the case of heavy doping of $[\mathrm{Si}] \sim 1 \times 10^{20} \mathrm{~cm}^{-3} \cdot{ }^{11}$

The formation of nanopipes can be controlled by the segregation of silicon to surface pits, and the growth kinetics on particular crystallographic planes, yet the critical event is 


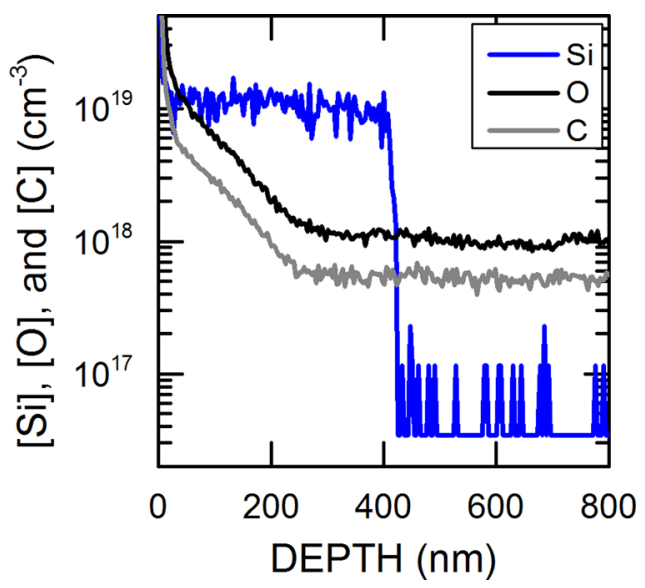

FIG. 3. SIMS depth profile of the atomic concentration of silicon, [Si], oxygen, $[\mathrm{O}]$, and carbon, $[\mathrm{C}]$, through the top part of a representative high-Alcontent AlGaN:Si/AlGaN/AlN-on-SiC layer structure.

the nucleation of the surface pits with lateral facets along the slow growth planes (10-11). ${ }^{19}$ Different factors may affect the surface roughening and nucleation of surface pits at any stage of the growth of the $\mathrm{Al}_{0.82} \mathrm{Ga}_{0.18} \mathrm{~N}$ layer structures, and consequently the emergence of nanopipes. Apparently, the onset of the Si doping favors the stabilization and development of preferential crystallographic facets, which follows the elaboration above about the gradual increase of the oxygen concentration within the doped layer. The gradual increase of the oxygen concentration is typically triggered with a certain delay after the onset of the Si doping (Fig. 3), being consistent with any transient period of facets formation.

Change in facet structure is seen on the example of the change of growth mode (two-dimensional to three-dimensional) of GaN by the application of a short flash of $\mathrm{SiH}_{4}{ }^{21}$ Opposite to that, flow of the precursor $\mathrm{Cp}_{2} \mathrm{Mg}$ is applied to decrease the tendency for faceting in the lateral epitaxial overgrowth of $\mathrm{GaN}^{22}$ We observe that doping of $\mathrm{Al}_{0.82} \mathrm{Ga}_{0.18} \mathrm{~N}$ layers at the high level of $[\mathrm{Mg}] \sim 2$ $\times 10^{19} \mathrm{~cm}^{-3}$ is not associated with the development of preferential crystallographic facets, respectively, nanopipes and related nanopits. The typical surface morphology of such layers is dominated by folded steps around the surface intersections of screw-component threading dislocations. ${ }^{23}$ Accordingly, these layers preserve compressive stress with no development of additional diffraction maximum on the reciprocal space maps, respectively, with no splitting of the $\mathrm{Al}_{0.82} \mathrm{Ga}_{0.18} \mathrm{~N}$ reflection in the XRD $2 \theta-\omega$ scans (Fig. 4).

In summary, the present study delineates basic mechanisms, which underlie the epitaxial growth of high-Al-content $\mathrm{Al}_{0.82} \mathrm{Ga}_{0.18} \mathrm{~N}$ layers doped by $\mathrm{Si}$. We discuss the development of certain facet structure (nanopipes) within the doped layers, which is apparent at the high Si doping levels implemented in this study, $[\mathrm{Si}] \sim 1 \times 10^{19} \mathrm{~cm}^{-3}$ and $3 \times 10^{19} \mathrm{~cm}^{-3}$. The formation of nanopipes influences the conductivity of the layers. It is anticipated to give rise to facets with SiN-related coverage, outcompeting the incorporation of $\mathrm{Si}$ at substitutional donor sites in the lattice. The formation of nanopipes and the incidence of related nanopits on the top surface of the layers correlate with high resistivity of the layers. We do not find evidence for kinetic stabilization

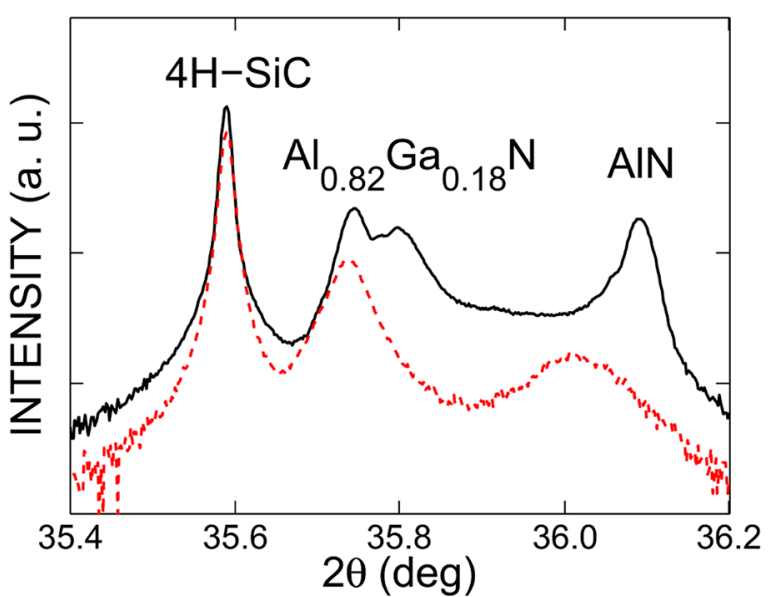

FIG. 4. XRD 20- $\omega$ scans of $\mathrm{Al}_{0.82} \mathrm{Ga}_{0.18} \mathrm{~N}: \mathrm{Si} / \mathrm{Al}_{0.82} \mathrm{Ga}_{0.18} \mathrm{~N} / \mathrm{AlN}$-on-SiC (black line) and $\mathrm{Al}_{0.82} \mathrm{Ga}_{0.18} \mathrm{~N}: \mathrm{Mg} / \mathrm{Al}_{0.82} \mathrm{Ga}_{0.18} \mathrm{~N} / \mathrm{AlN}$-on-SiC (red dashed line) structures taken in the vicinity of the $\mathrm{Al}_{0.82} \mathrm{Ga}_{0.18} \mathrm{~N}$ (0002) reflection. The doping level corresponds to $[\mathrm{Si}] \sim 1 \times 10^{19} \mathrm{~cm}^{-3}$ and $[\mathrm{Mg}] \sim 2 \times 10^{19} \mathrm{~cm}^{-3}$, respectively.

of preferential crystallographic facets when a flow of $\mathrm{Cp}_{2} \mathrm{Mg}$, instead of $\mathrm{SiH}_{4}$, is implemented in the doping process. Even the highly Mg-doped layers preserve compressive stress, and their morphology is determined by folded steps. The relaxation of the large tensile strain near the surface of the highly Si-doped layers promotes flat surfaces.

Support from the Swedish Research Council (VR) and Linköping Linnaeus Initiative for Novel Functional Materials (LiLi-NFM, VR) is gratefully acknowledged. A.K.G. acknowledges support from the Swedish Governmental Agency for Innovation Systems (VINNOVA).

${ }^{1}$ A. E. Romanov, G. E. Beltz, P. Cantu, F. Wu, S. Keller, S. P. DenBaars, and J. S. Speck, Appl. Phys. Lett. 89, 161922 (2006).

${ }^{2}$ D. M. Follstaedt, S. R. Lee, A. A. Allerman, and J. A. Floro, J. Appl. Phys. 105, 083507 (2009)

${ }^{3}$ A. E. Romanov and J. S. Speck, Appl. Phys. Lett. 83, 2569 (2003).

${ }^{4}$ P. Cantu, F. Wu, P. Waltereit, S. Keller, A. E. Romanov, S. P. DenBaars, and J. S. Speck, J. Appl. Phys. 97, 103534 (2005).

${ }^{5}$ P. Cantu, F. Wu, P. Waltereit, S. Keller, A. E. Romanov, U. K. Mishra, S. P. DenBaars, and J. S. Speck, Appl. Phys. Lett. 83, 674 (2003).

${ }^{6}$ D. M. Follstaedt, S. R. Lee, P. P. Provencio, A. A. Allerman, J. A. Floro, and M. H. Crawford, Appl. Phys. Lett. 87, 121112 (2005).

${ }^{7}$ J. F. Wang, D. Z. Yao, J. Chen, J. J. Zhu, D. G. Zhao, D. S. Jiang, H. Yang, and J. W. Liang, Appl. Phys. Lett. 89, 152105 (2006).

${ }^{8}$ I. C. Manning, X. Weng, J. D. Acord, M. A. Fanton, D. W. Snyder, and J. M. Redwing, J. Appl. Phys. 106, 023506 (2009).

${ }^{9}$ J. Dion, Q. Fareed, B. Zhang, and A. Khan, J. Electron. Mater. 40, 377 (2011).

${ }^{10}$ F. Brunner, A. Mogilatenko, V. Kueller, A. Knauer, and M. Weyers, J. Cryst. Growth 376, 54 (2013).

${ }^{11}$ A. Kakanakova-Georgieva, D. Nilsson, X. T. Trinh, U. Forsberg, N. T. Son, and E. Janzén, Appl. Phys. Lett. 102, 132113 (2013).

${ }^{12}$ S. Pereira, M. R. Correia, E. Pereira, K. P. O'Donnell, E. Alves, A. D. Sequeira, N. Franco, I. M. Watson, and C. J. Deatcher, Appl. Phys. Lett. 80, 3913 (2002).

${ }^{13}$ F. M. Morales, J. M. Mánuel, R. García, B. Reuters, H. Kalisch, and A. Vescan, J. Phys. D: Appl. Phys. 46, 245502 (2013).

${ }^{14}$ Y. H. Xie, G. H. Gilmer, C. Roland, P. J. Silverman, S. K. Buratto, J. Y. Cheng, E. A. Fitzgerald, A. R. Kortan, S. Schuppler, M. A. Marcus, and P. H. Citrin, Phys. Rev. Lett. 73, 3006 (1994).

${ }^{15}$ P. Vennégues, Z. Bougrioua, J. M. Bethoux, M. Azize, and O. Tottereau, J. Appl. Phys. 97, 024912 (2005).

${ }^{16}$ K. Cheng, M. Leys, S. Degroote, H. Bender, P. Favia, G. Borghs, and M. Germain, J. Cryst. Growth 353, 88 (2012). 
${ }^{17}$ J. Elsner, R. Jones, M. Haugk, R. Gutierrez, Th. Frauenheim, M. I. Heggie, S. Öberg, and P. R. Briddon, Appl. Phys. Lett. 73, 3530 (1998).

${ }^{18}$ M. E. Hawkridge and D. Cherns, Appl. Phys. Lett. 87, 221903 (2005).

${ }^{19}$ Z. Liliental-Weber, Y. Chen, S. Ruvimov, and J. Washburn, Phys. Rev. Lett. 79, 2835 (1997).

${ }^{20}$ A. Kakanakova-Georgieva, D. Nilsson, and E. Janzén, J. Cryst. Growth 338, 52 (2012).
${ }^{21}$ H. Lahreche, P. Vennégues, B. Beaumont, and P. Gibart, J. Cryst. Growth 205, 245 (1999).

${ }^{22}$ B. Beaumont, S. Haffouz, and P. Gibart, Appl. Phys. Lett. 72, 921 (1998).

${ }^{23}$ A. Kakanakova-Georgieva, D. Nilsson, M. Stattin, U. Forsberg, Å. Haglund, A. Larsson, and E. Janzén, Phys. Status Solidi - RRL 4, 311 (2010). 